\title{
Filippo Salvatore Gilij S.J. (1721- 1789): Contribuciones para el conocimiento de la Venezuela y la cuenca orinoquense en el siglo XVIII
}

\author{
Filippo Salvatore Gilij S.J. (1721-1789): his contributions to the \\ knowledge of Venezuela and the Orinoco Basin in the $18^{\text {th }}$ century
}

Marie-Claude Mattei-Müller ${ }^{1}$

\begin{abstract}
Resumen
De sus 18 años de permanencia en el medio Orinoco, el padre Gilij legó un invalorable testimonio plasmado en los cuatro tomos de su Ensayo de Historia Americana o sea Historia Natural, Civil y Sacra de los Reinos y de las Provincias españolas de Tierra Firme en la América Meridional, cuya versión original en italiano fue editada entre 1780 y 1784. En esta obra Gilij abordó, con una visión enciclopédica y una metodología en muchos aspectos moderna, las facetas más diversas y más inéditas del territorio venezolano de aquella época: su geografía, dando informaciones precisas referentes a la red fluvial orinoquense, a su toponimia, a sus orígenes y su interconexión con la cuenca amazónica, sus variaciones climáticas relacionadas con la alternancia de lluvia y sequía, sus recursos naturales, en particular de flora y fauna. Proporciona numerosos datos relativos al valor alimenticio u otros usos de los mamíferos, como también de aves, peces, reptiles e insectos. Para la flora describe los múltiples usos tanto de las plantas silvestres como de las cultivadas. Pero los dominios que quizás cautivaron más su atención y sobre los cuales dejó documentos de suma importancia pertenecen al conocimiento antropológico de los pueblos originarios que encontró y con los cuales vivió en la cuenca del Orinoco. De estos pueblos Gilij estudió y describió no solo sus lenguas, sus modos de vida y sus ritos, sino también sus conocimientos de la naturaleza, sus sistemas agrícolas, su utilización razonable de los espacios geográficos. Aun más, supo apreciar la belleza tanto de sus lenguas como de sus paisajes. En este artículo destacamos la importancia de Gilij en los diversos campos de las ciencias naturales y como precursor de la lingüística amerindia y pionero en diversos campos de la americanística.
\end{abstract}

Palabras clave: F.S. Gilij, cuenca del Orinoco, lenguas orinoquenses, etnografía orinoquense, estudios naturalistas en el Orinoco.

\begin{abstract}
Father Gilij left an invaluable testimony of his 18 years' stay in the Orinoco region in the four volumes of his Saggio di storia americana; o sia, storia naturale, civile e sacra de regni, e delle provincie spagnuole di Terra-Ferma nell' America Meridionale descritto dall' abate F. S. Gilij, originally edited in Italian between 1780 and 1784. With encyclopedic vision
\end{abstract}

${ }^{1}$ Profesora de Lingüística de la Universidad Central de Venezuela y Consultante del Instituto Nacional de Estadísticas en la gerencia del Censo Indígena de Venezuela. E-mail: marieclaudemat@gmail.com 
and a methodology in many ways modern, in this work Gilij addressed the most diverse and unprecedented dimensions of the Venezuelan territory of the time: its geography, with precise information on the Orinoco river system, its toponymy, its origins and interconnection with the Amazon basin, its climate variations regarding alternation of rains and drought, its natural resources, particularly of flora and fauna. He provides numerous data about the nutritional value and other uses of mammals, and also of birds, fish, reptiles and insects. As for the flora, he describes the many uses for wild and cultivated plants. But the domains that perhaps enthralled him the most, of which he left extremely important documents, refer to the anthropological knowledge of the native peoples he encountered and with whom he lived near the Orinoco basin. Gilij not only studied and described the languages of these peoples, their ways of life and rites, but also their knowledge of nature, their agricultural systems, their rational use of geographical space. Moreover, he was able to appreciate the beauty of their languages and landscapes. In this article, we highlight the importance of Gilij in the different fields of natural science and as precursor of Amerindian linguistics and pioneer in the diverse fields of American studies.

Key words: F.S. Gilij, Orinoco basin, Orinoco languages, Orinoco ethnography, natural history of the Orinoco area.

\section{Contribuciones al conocimiento de la cuenca orinoquense}

Al salir de Venezuela, en marzo 1768, el jesuita Filippo Salvatore Gilij (1721 - 1789) partió con el solo recuerdo de sus veinte y cinco años de Tierra Firme en el continente sudamericano. El decreto del monarca español Carlos III (1767), que puso fin a las misiones jesuíticas en este continente, fue ejecutado de manera drástica, por no decir agresiva. En efecto, Gilij no sólo sufrió el destierro, las autoridades españoles de aquel entonces lo despojaron de todos sus documentos, de sus apuntes gramaticales, mapas, diccionarios y de sus relatos de los pueblos originarios que visitó y con los cuales convivió, en particular los Tamanacos y los Maipures. Había pasado más de dieciocho años con ellos. A pesar de las adversidades, Gilij emprendió la ardua y valiente tarea de plasmar, lejos de Tierra Firme, gran parte de sus vivencias, de sus descubrimientos así como las más diversas informaciones referentes no sólo a la naturaleza sino también y, sobretodo, a las poblaciones de la Cuenca del Orinoco y la Amazonia venezolana. En su "Prefacio", dedicado a los "eruditos lectores", Gilij explica cuáles fueron sus motivaciones al escribir la gran obra Ensayo de Historia Americana, publicada en Roma entre los años 1780 y 1784 , enteramente escrita en su tierra natal, Italia $^{2}$. Analizaremos aquí sus objetivos y

\footnotetext{
${ }^{2}$ El título completo es: Saggio di Storia Americana; o sia Storia Naturale, Civile e Sacra de'Regni e delle provincie Spagnuole di Terra Ferma nell'America Meridionale. Todas nuestras citas provienen de la traducción al español de los tomos I, II, y III a cargo de Antonio Tovar, edición de la Academia Nacional de Historia (Caracas, 1965), y la del tomo IV a cargo de Mario Germán Romero, edición de la Biblioteca de Historia Nacional de Colombia (Bogotá, 1955).
} 
sus alcances, prestando particular atención al contexto histórico y filosófico en el cual se inserta esa obra.

\section{Visión enciclopédica crítica y metodología}

Gilij pertenece al Siglo de las Luces, un período marcado por el movimiento enciclopédico, aquella verdadera revolución intelectual que, por numerosos descubrimientos científicos en múltiples campos (astronomía, química, botánica, zoología, ciencias del hombre y de la naturaleza en general), llevó también a una revolución financiera e industrial. El misionero jesuita no estuvo de acuerdo, como el mismo lo afirmó en varias oportunidades en su obra, con todas las teorías de su tiempo, sin embargo estaba impregnado de la curiosidad propia de la Ilustración y compartió con muchos de los científicos contemporáneos el anhelo de conocer y explicar el hombre y el mundo en todas sus facetas. Su obra ofrece - no siempre con igual precisión ni en la misma cuantía - datos etnográficos, botánicos, zoológicos, mineralógicos y geográficos - en particular referentes a hidrología y a climatología -, así como históricos, filosóficos y religiosos, además de otros en los más diversos campos. Consciente de sus limitaciones por la complejidad y diversidad, por la cantidad de las materias tratadas y por la inmensidad del continente americano, Gilij define su exposición como un "bosquejo" (1965: I, 20), centrando la atención principalmente en la cuenca del Orinoco y muy particularmente el Orinoco medio, que este personaje tuvo el privilegio de recorrer tanto por vía fluvial como terrestre.

El autor del Ensayo de Historia Americana se presenta ante todo como un "observador curioso y exacto" (1965: I, 21), revindicando como objetivo fundamental la búsqueda de la verdad ${ }^{3}$. Critica severamente a los que se atreven a escribir sobre el continente americano sin haber tenido lo que él llama la "experiencia de América", es decir el conocimiento directo in situ, de visu. Además de su propia experiencia, Gilij recurre a todas las fuentes posibles de información fidedigna, solicitando la particular colaboración de sus acompañantes indígenas, que eran sin duda los mejores conocedores de aquellas regiones. Sus principios metodológicos son claramente expuestos en el tomo cuatro de su Ensayo: "me he servido de tres medios eficacísimos: de

\footnotetext{
3 "Y supuesto que el primer fin de quien escribe historia ha de ser el de decir la verdad, ya sea agradable o desagradable, hay que hablar de los dos reinos de la naturaleza, el animal y el vegetal, separando su virtudes y miserias según los climas. El reino mineral no está sujeto a tales variaciones" (Gilij 1955: IV, 78).

4 "El prurito de formar libros sobre cosas no bien comprobadas ha inducido a no pocos a tejer una fábula sobre las comarcas de América. Cualquiera que ha estado allí y ha observado con ojo al menos no desatento las muchas cosas rarísimas de aquel continente antes desconocido, es necesario que se asombre después al ver la imagen de él tan diversa en los diversos escritores" (Gilij 1965: I, 45)
} 
mis ojos, de mis oídos y de los fieles relatos de los demás" (1955: IV, 19) y al respecto precisa:

Me sirvo de todos, de todos escojo lo mejor pero nada más; ya que yo, no sé por que innata libertad en este punto, que conozco muy bien, no sigo ciegamente el modo de pensar de los demás, salvo en aquello en que no se apartan de la verdad. (ibidem)

A diferencia de otros viajeros, cronistas y misioneros que visitaron esta región, Gilij vislumbró rápidamente la extrema riqueza en recursos naturales del territorio que hoy constituye una gran parte de Venezuela:

Todo el país tiene vegetales, animales, metales y rarezas que no se encuentran ordinariamente en los otros. Yo en el Orinoco observé con estupor muchas veces esta notabilísima variedad. Otras plantas por ejemplos las encontrareis en las orillas, otras tierra adentro, otras en los montes, otras en las llanuras, otras cerca, otras lejos. De tal manera que puede decirse ayuno sobre el estado natural del Orinoco al que, aunque haya estado allí muchos años, no vio nunca los países interiores. $(1965:$ I, 296)

En este último comentario, Gilij alude a la visión parcial y errónea de varios de sus contemporáneos, como el franciscano Antonio Caulín (1719-1802), que pasó 16 años en América y trazó un amplio panorama de la región en su Historia Corográfica, Natural y Evangélica de Nueva Andalucía, Provincias de Cumaná, Nueva Barcelona, Guayana y Vertientes del rio Orinoco ${ }^{6}$, sin haberse adentrado mucho en las áreas que Gilij llama de los "países interiores del Orinoco", a los cuales dedica la casi totalidad del tomo I de su Ensayo de Historia Americana.

\section{Un geógrafo de terreno y precursor de la geografía moderna}

Cuando Gilij pisa tierra americana, al iniciarse la segunda mitad del siglo XVIII, la principal y más difundida fuente de información referente a la cuenca del Orinoco era El Orinoco ilustrado y defendido, una obra publicada en 1731, de autoría del padre José Gumilla (1686-1750), misionero y miembro, como él, de la Compañía de Jesús. Gilij señaló en muchas oportunidades la importancia invalorable de la obra de Gumilla para el conocimiento de lo que llama Tierra Firme, sin embargo, no duda en afirmar que, cuando él llegó, las tierras y las aguas de la cuenca orinoquense aún eran en gran parte desconocidas. Es así como escribe: "Cuando yo llegué allí en 1749, aunque se hubiera viajado mucho por los ríos de este territorio, no era aún conocida más que una parte pequeñísima" (1965: I, 126).

\footnotetext{
5 "ayuno". es la palabra usada por el traductor, en un sentido figurado: que no tiene noticias de lo que se habla.

${ }^{6}$ Caulin terminó esta obra en 1759 pero fue publicada por primera vez en 1779. Desde luego, Gilij tuvo oportunidad de conocer esta obra antes de concluir la suya.
} 
El jesuita italiano inicia su obra con unas "noticias generales del Orinoco" (1965: I, 36-86), que constituyen su más notable e indiscutible contribución al conocimiento de la red fluvial de la cuenca orinoquense. Ofrece una descripción minuciosa de ese gran río, señalando recodos, playas, islas, rocas, cascadas, monumentos naturales como el cerro Aután, bosques galerías, peligrosos raudales como el de Atures, aldeas indígenas viejas y nuevas, fortines viejos y nuevos, misiones o reducciones. Le sorprende la anchura del Orinoco y su longitud; su inmensidad así como el volumen y la fuerza del agua en el delta; indica detalladamente la posición y la importancia de sus afluentes (ribera izquierda y ribera derecha). Destaca oportunamente la intercomunicación fluvial OrinocoCasiquiare-Rio Negro-Marañón ${ }^{7}$, negada por Gumilla en la primera edición de su obra (1731). Gilij no fue el descubridor de esta conexión, sin embargo fue el primero en relatar con detenimiento las peripecias de la famosa excursión que, partiendo de Carichana en el río Orinoco, en febrero de 1744, llevó al padre Manuel Román a este importantísimo descubrimiento (1965: I, 53-57).

En lo que concierne el origen del Orinoco, Gilij refuta las hipótesis de muchos escritores, entre otros también de su maestro Gumilla, que en aquel entonces situaban erróneamente las fuentes del Orinoco en los Andes colombianos, más precisamente en los "montes de Popayán" (1965: I, 45). Fue necesario esperar dos siglos más (hasta 1951) para conocer el verdadero lugar de nacimiento del Orinoco. Pero la hipótesis de Gilij no estaba tan lejos de la verdad. "Pasando ahora a la verdadera fuente del Orinoco, no parece dudoso en nuestros días que no esté o en la laguna Parime o al menos en su vecindad." (1965: I, 46)

Uno de sus aportes más relevantes para el conocimiento de esta red fluvial es su análisis de las fluctuaciones del nivel de las aguas, debidas a la particularidad del régimen pluvial del área, caracterizado por la alternancia sistemática de una temporada de lluvia y otra de sequía durante el año:

El Orinoco crece de modo regular -desde el mes de marzo hasta el fin de julio [...] el mes de agosto está casi inmóvil el Orinoco. Es verdad que duran todavía las lluvias pero aunque estrepitosas, son raras y no llevan aumento sensible al río. Añádase que hacia el fin de agosto, meses en que son muchas las lluvias en el bajo Orinoco, son quizá pocas hacia sus fuentes y comienza el río a bajar (1965: I, 36-37).

Por lo demás, es menester subrayar que Gilij registró gran parte de la toponimia indígena ${ }^{8}$ de aquella época, transcribiendo los nombres que los pobladores indígenas daban en sus respectivas lenguas a los ríos, los cerros, las comunidades, los lugares y los pueblos de su territorio. Este registro constituye una herramienta de gran valor para la interpretación de los antiguos mapas y para

\footnotetext{
7 "No repetiré aquí inútilmente el viaje del Padre Román, primer descubridor del Casiquiare y de la comunicación de éste con el Marañón” (1965: I, 128)

${ }^{8}$ Ver Adolfo Salazar-Quijada. La toponimia en Venezuela. Caracas, 1978: 83
} 
la ubicación de los territorios ancestrales de los pueblos indígenas presentes en aquella zona en el siglo XVIII.

Antes de Gilij, varios misioneros jesuitas, nominalmente, Mathias de Tapia, Juan Capuel, José Gumilla, Manuel Román y Bernardo Rotella, habían desarrollado una labor cartográfica significativa. ${ }^{9} \mathrm{Y}$ el propio Gilij incluyó tres mapas en su Ensayo de Historia Americana: en el primer tomo, el Mapa del Río y Provincia del Orinoco en la América Meridional, que fue el único mapa esbozado por él; en el segundo tomo, el Mapa Corográfico de todo el Curso del Río Orinoco; y en el cuarto tomo, el Mapa geográfico de Tierra Firme, o sea, del Nuevo Reino de Granada. Los dos últimos mapas fueron dibujados por el Padre Veiga con base en otros mapas. Gilij reconoce las deficiencias de su mapa ${ }^{10}$ y lamenta no haber tenido los instrumentos necesarios para determinar las coordenadas geográficas, sin embargo las indicaciones muy precisas, que abundan en su obra, ayudan a tener una visión bastante exacta del curso del río Orinoco, en particular del Orinoco Medio.

El historiador Manuel A. Donis Ríos, analizando el papel de Gilij en la cartografía de la Orinoquía, afirma:

Aunque ciertamente el Mapa del Río y Provincia del Orinoco es muy esquemático contiene una información muy valiosa particularmente del curso medio del Orinoco, reflejando acertadamente la hidrografía de nuestro gran río y algunos accidentes geográficos muy representativos de la Orinoquia venezolana, especialmente los visitados por su autor [...]. Su mapa evidencia avances en la representación de la red fluvial del Orinoco. (1989: 210, 214)

Y el geógrafo Pedro Cunill Grau, experto conocedor de la obra del jesuita, lo presenta como "uno de los precursores de la geografía moderna por su visión holística al aplicar el principio de la globalidad terrestre" (1989: 27). En varios capítulos de su obra, Gilij analiza las relaciones entre los accidentes de la geografía física, las potencialidades de los recursos naturales y las variaciones de los fenómenos climáticos según el periodo del año y según el área. Como mencionamos anteriormente, Gilij hace hincapié en la ocurrencia de las dos estaciones anuales que caracterizan el clima tropical:

Dos solas y no cuatro, como sucede entre nosotros, son en Orinoco las estaciones del año, siendo en los tiempos dos solas las variaciones que en el curso de un año se observan por los habitantes. Dividen el año todo en dos tiempos. Unos son hermosos y serenos y a éstos llaman verano. Otros son tristes y lluviosos y a éstos llaman invierno." (1965: II, 32-33).

\footnotetext{
${ }^{9}$ Ver José del Rey Fajardo S. J. Apuntes para una Historia de la Cartografía Jesuítica en Venezuela. Boletín Histórico de la Fundación Boulton, Caracas, núm. 38 (1975).

${ }^{10}$ En este mapa Gilij sitúa el lugar de nacimiento del Orinoco en el "hipotético" lago Parime (ver mapa).
} 


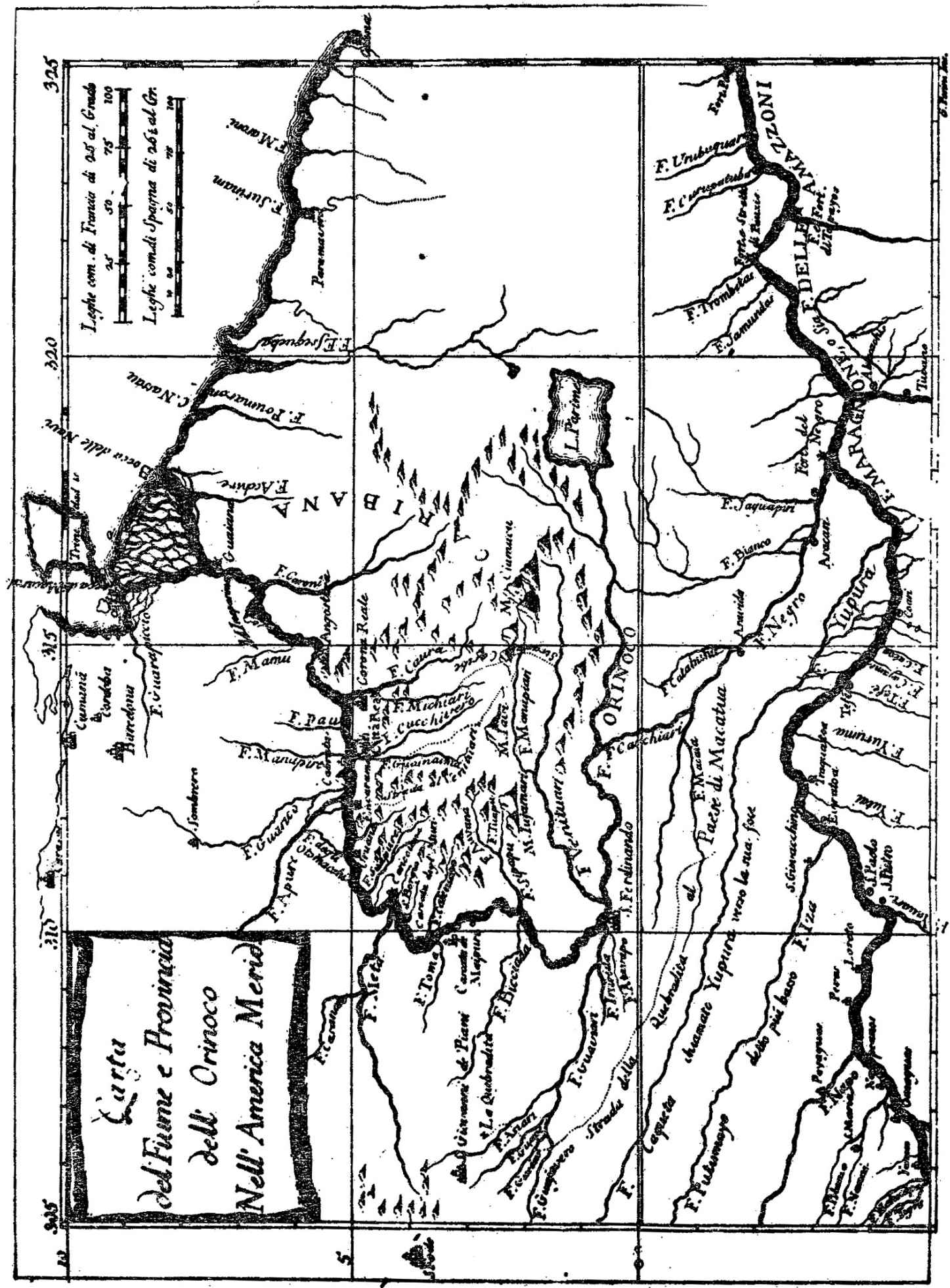


Analiza sus efectos no sólo en el comportamiento de los ríos, sino también en la calidad de los suelos, ${ }^{11}$ así como en la vida misma de los pobladores. Señala con mucho acierto la fertilidad de los suelos de las islas muy boscosas que emergen en el Orinoco, comparándolas a las del Nilo, por beneficiarse cada año de los depósitos fertilizantes, arrastrados por el río durante las crecidas ${ }^{12}$.

Pertinentes también son sus observaciones relativas a otros fenómenos asociados a la ocurrencia de las dos estaciones, como el graznar del mono araguato, el florecer del araguaney y el germinar de los ñames guardados en verano, que son señales anunciadoras de la temporada de lluvias. Sus interpretaciones de las influencias climáticas no se limitan a las variaciones del nivel de las aguas de los ríos, sino también a sus posibles repercusiones sobre la salud de los seres humanos, por ejemplo, el beneficio de la exudación y la bondad de las temperaturas más calientes para las personas de más edad.

Sus conclusiones no fueron siempre acertadas, como la relación que propone entre el calor tropical y la pequeñez de los mamíferos existentes en la selva tropical. Tampoco escapa totalmente a las visiones míticas del Orinoco que, desde el siglo XVI, prosperaban en la imaginación de los viajeros, como los mitos de El Dorado, del Lago Parime (1965: I, 288 a 290) y de las Amazonas (ibidem, 150).

\section{Gilij, agudo observador de la flora y la fauna}

El misionero italiano no esconde su asombro frente a la diversidad y la abundancia de los recursos naturales, tanto de animales (pájaros, peces, mamíferos, insectos, batracios, serpientes), como en particular de plantas que encontró en las orillas de los ríos, en los bosques, en los cerros y en las llanuras.

La obra de Gilij contiene un sinfín de informaciones novedosas para el conocimiento de la flora orinoquense. Además de divulgar la existencia de numerosas plantas desconocidas hasta aquel entonces en Europa, revela los múltiples usos y beneficios que se pueden sacar de ellas. Señala, por ejemplo, la presencia de la canela orinoquense, descubierta por el padre Francisco Olmo en 1746, y la de cacaotales en el Alto Orinoco, descubierta por la expedición de Francisco Bobadilla (1965: I, 169), así como también de la vainilla (1965:

\footnotetext{
11 "Y para hablar primeramente de la tierra, hacia el Orinoco no es ordinariamente fértil ni buena. Es comúnmente rojiza y lo que es peor arenosa. En el invierno por lo demás es óptima para sembrar en ella maíz, frijoles y otras cosas propias de aquel clima. Pero en los tiempos secos, es de poquísima utilidad. Los países alejados del Orinoco, particularmente en los matos, son de terreno mejor." (1965: I, 21 y II, 25).

12 " [...] todas o casi todas (las islas fluviales) en las lluvias periódicas se inundan. El terreno de estas islas, fecundado por el Orinoco, como las campiñas egipcias del Nilo, es muy fértil y está vestido todo de árboles hermosísimos" (1965: I, 43).
} 
I, 168-169) que crecía en territorio de los Parecas, vecinos de los Tamanacos.

Gracias a su observación concienzuda de las prácticas y estrategias implementadas por los pueblos indígenas, tanto en la selección y preparación de los suelos para sus cultivos, como en la explotación de los recursos vegetales silvestres, supo evaluar la particular importancia de algunos productos como el maíz, el tabaco y la caña de azúcar. Destacó el papel preponderante de las raíces cultivadas (yuca, batata, ocumo, ñame y jengibre) y también de los cultivos de frijol, quinchoncho, maní, auyama, pimentón, ají y taparo y de muchas frutas (patilla, piña, lechosa, merey y banana). En lo que concierne a las plantas silvestres, llamó particularmente su atención la variedad sorprendente de árboles frutales que crecen en la selva tropical y cuyas frutas representan un suplemento alimenticio fundamental cuando se está lejos del asentamiento comunitario y de los conucos. Gilij hace una reseña detallada de las frutas ${ }^{13}$ que consumió durante sus expediciones exploratorias, describiendo tanto las propiedades positivas como las negativas.

Entre las numerosas virtudes de la flora orinoquense, además del valor alimenticio de muchas de estas plantas, Gilj resaltó los diversos usos que los indígenas daban a las diversas especies vegetales. ${ }^{14} \mathrm{Y}$ señaló con particular atención las propiedades de los árboles utilizados en la fabricación de las curiaras, i.e., de los medios de transporte por excelencia en esta vasta red fluvial.

La madera de que se hacen las curiaras es abundantísima en el Orinoco, [unos] la[s] hacen de cedro, pero éste es traído de lejos por las inundaciones; otros de salsafrás, y otros de cierto árbol llamado María, del que saca el famoso bálsamo del mismo nombre [...]. No todas las maderas son durables y capaces de servir por largo tiempo en el agua. Las arriba citadas son las mejores y se prefieren a todas las demás. (1965: I, 80)

No se limita a dar las características de los árboles, sino que añade, para los más buscados como el cedro, su lugar de procedencia ${ }^{15}$ y la forma en que la madera es trasladada hasta el lugar de procesamiento. Además, describe las diversas técnicas de fabricación de las canoas, con sus diferentes tamaños,

\footnotetext{
13 "Hube de mantenerme mucho tiempo con frutas salvajes o algún pescado ahumado, sin tener sino rarísimas veces el cazabe" (1965: III, 68).

14 "Los orinoquenses tienen raíces cultivadas y comestibles, tienen semillas y frutos, tienen vegetales de donde sacar a su manera el vestido, tienen finalmente con qué adornar la persona y que les sirve para presentarse decentemente entre sus connacionales." (1965: I, 188).

15 "El verdadero cedro se ve también, y en los tiempos lluviosos bastante a menudo es traído por las riadas. Estos cedros vienen del Meta o bien del Apure, ríos en cuyas orillas se encuentran, viéndolos a los lejos bajar como naves, llevados todos enteros con las raíces con ramas, los orinoquenses los sacan con cuerdas a cualquier ensenada para trabajarlos y hacer canoas" (1965: I, 118-119).
} 
según las prácticas de los pueblos indígenas, observando también los diferentes tipos de remos y los modos de remar (1965: I, 78-81).

Minuciosas son sus observaciones sobre las bondades y usos de numerosos árboles, entre los que comenta el palo de aceite, el paraguatán, el pardillo, el cartán, el araguaney y la ceiba o cumaca con sus frutos llenos de lanilla sedosa. Según Pedro Cunill Grau, Gilij fue un precursor en descubrir las potencialidades de esta lanilla, dado que "en los comienzos del siglo XX, esta lanilla, conocida como kapok en Asia, tomó una considerable importancia en el comercio mundial" (1989: 49). Al respecto el misionero explorador escribió: "De utilidad mayor podría ser una especie de algodón o de seda que se encuentra en el fruto de la cumaca. Se dice que es excelente para rellenar colchones" (1965: I, 59).

Entre las plantas utilitarias, nombra las que sirven como pegamento, tal como la resina peramán, las que sirven como fibras textiles, sumamente importantes en los trabajos de cestería, tales como los bejucos itiriti (Ischnosiphon spp.), el mamure (Heteropsis flexuosa), la cocuiza o agave (Fourcroy humboldtiana), el algodón (Gossypium spp.), las palmas (Araceae); las que sirven como pinturas corporales o tintes para tejidos, tales las semillas del onoto (Bixa orellana), las hojas de la chica silvestre trepadora (Arrabidea chica H.B.K.), los frutos del caruto (Genipa americana); las que sirven como remedios, en fin.

A ese respecto, Gilij no fue el primero en reportar los métodos curativos de los indígenas americanos. Sin embargo, todas las informaciones que recogió con los Tamanacos y los Maipures, con los cuales compartió tantos años, fueron datos muy útiles para las investigaciones realizadas posteriormente en este campo. Entre los remedios mencionados por Gilij están el bálsamo sacado del copaiba o palo de aceite (Copaifera officinalis), utilizado como cicatrizante; las infusiones elaboradas con hojas del cariaquito colorado (Lantana cámara) o con semillas de onoto (Bixa Orellana) o con frutos y retoños de guamacho (Pereskia guamacho); todas plantas utilizadas contra las fiebres; otras como el bototo o carnestolenda (Cochlospermum vitifolium), utilizado contra la pleuresía; las frutas de esponjilla (Luffa operculata), contra el estreñimiento; las cocciones de corteza de merey (Anacardium occidentale ) o raíces de guayabito o guayabofresa (Psidium cattleianum), utilizadas contra la disentería; las raíces de la escorzonera o salsifí negro (Scorzonera hispanica), como diurético. Reporta también el uso de contravenenos, en particular el uso de las hojas de tabaco y del jugo de tabaco contra las mordeduras de serpientes venenosas. En este sentido, Gilij puede ser considerado como un precursor de la etnomedicina del Orinoco medio.

Cuatro capítulos del tomo II (concretamente, los capítulos XVI a XIX) están dedicados a las prácticas chamánicas. Para el misionero italiano, como para sus contemporáneos, los chamanes no tienen poder de sanación porque son representantes del mal, y sus actuaciones como el soplo del tabaco, los 
ensalmos, el golpe de la maraca sagrada para ponerse en contacto con los poderes celestiales o la succión del cuerpo del paciente, no podían ser sino "supersticiosos remedios", "charlatanerías", y obras de un "espíritu diabólico". Sin embargo atribuye a los piaches (chamanes) un buen conocimiento de hierbas beneficiosas para la salud y otros fines.

Para la observación de la fauna, Gilij era consciente de su falta de competencia, de modo que la mirada que dirige a los animales es esencialmente pragmática y utilitaria.

No me atribuyo el mérito de haberlos descrito perfectamente en todas sus partes y según las leyes que agradan a los mejores naturalistas. No me era posible hacer en ésta como en todas las demás partes de la historia natural, un relato minucioso, propio sólo de aquellos que dejado todo de otro empleo, se entregan enteros a la contemplación de la naturaliza. (1965: I, 20-21)

Se dedicó a describir los diferentes hábitat, según el territorio, sea ribereño, sabanero, selvático o montañero, y a analizar los respectivos valores alimenticios, comerciales u otros, como por ejemplo, para artículos de artesanía. Su registro de la fauna orinoquense, sea de peces, anfibios, reptiles, aves, sean acuáticas, sabaneras o montañeras, de mamíferos en sus diversas especies o también de insectos, es mucho más amplio que el de Gumilla y Caulín. Alaba no sólo el valor alimenticio, sino también el buen sabor de la carne de varias aves, de patos y de paujíes en particular, de varios mamíferos (danta, venado, araguato) $\mathrm{y}$ en algunos casos arroja una observación conservacionista en beneficio de la salvaguardia de los recursos animales presentes en el Orinoco medio. Critica, por ejemplo, la recolección masiva de los huevos de tortugas, animales que tienden a escasear siempre más.

No es la única "mirada ecológica" en la obra. Gilij señala una extracción excesiva del aceite del copaiba, que amenaza seriamente la supervivencia de este árbol:

Buscada hoy y perseguida por los españoles y los indios[,] la márana se ha convertido en rarísima en el Orinoco. No se corta ciertamente el gran tronco pero ¿qué importa? Se horada para sacar el jugo, impunemente por todos. $(1965: \mathrm{I}, 158)^{16}$

\section{Visión de los pueblos americanos}

Dos siglos y medio de conquista y de colonización habían ya transcurrido cuando llegó Gilij a América. Las poblaciones orinoquenses que tuvieron que afrontar los primeros asaltos de este proceso colonizador y evangelizador, habían

${ }^{16}$ Márana es el nombre del copaiba o palo de aceite en tamanaco. 
ya sufrido algunos cambios en su organización socio-económica, en sus modos de vida, en sus propias concepciones del mundo. Habían experimentado nuevas tecnologías, como las herramientas de hierro y las armas de fuego, nuevas relaciones de poder y nuevas relaciones comerciales con los nuevos pobladores provenientes en su mayoría de Europa. En ese contexto, Gilij da testimonios no sólo de los aspectos más tradicionales y originales de las culturas orinoquenses vigentes en el siglo XVIII, sino también de las transformaciones y señas de transculturación que habían empezado a quebrantar la identidad intrínseca de dichas culturas.

Propone una vez más una visión holística, fundada en el principio de la correlación necesaria entre ambiente natural y organización social. Según él, los espacios geográficos determinan en gran medida los modos de vida de los pobladores de la cuenca orinoquense.

Mi historia tiene por objeto principalísimo los índios [...] Ahora bien, ¿qué concepto formar de esta gente, poco conocida por nosotros, si se ignora del todo la tierra en que habita, se sabe poco de las aguas que bebe, nada del genio del cielo bajo el que está, nada del sol que la protege? (1965: II, 23)

En su afán por alcanzar la verdad ${ }^{17}$, Gilij no vacila en distanciarse de las teorías supuestamente científicas sobre el hombre americano, divulgadas por la Ilustración europea en obras de envergadura como la Enciclopedia, editada por Dideroty d'Alembert entre 1750 y 1765 . Gilij polemiza con la obra del naturalista francés Buffón ${ }^{18}$, con las ideas del abate holandés Cornelius de Pauw ${ }^{19}$ y de su colega francés el abate Raynal, algunos de los más destacados defensores de la llamada "teoría degeneracionista", según la cual la población del Nuevo Mundo sería inherentemente inferior a la europea, sosteniendo que los climas extremos, la humedad y otras características atmosféricas debilitarían tanto a animales como a humanos. De Pauw describe los pueblos indígenas americanos, en los siguientes términos en el "Discurso Preliminar" de su tratado:

Si hemos descrito a los Americanos como una raza humana que tiene todos los defectos de los niños, como una especie degenerada del género humano, cobarde, impotente, sin fuerza física, sin vigor,

\footnotetext{
17 "Me he abierto el camino para hablar brevemente del sistema que no es buffoniano, no de Linneo, sino verdadero"(1965: IV, 77).

${ }^{18}$ Georges-Louis Leclerc, conde de Buffon, Histoire naturelle générale et particulière. París, 1749-1789.

19 De Pauw (1739-1799) publicó en francés su tratado Recherches philosophiques sur les Américains, ou Mémoires intéressants pour servir à l'Histoire de l'Espèce Humaine (Berlín, 1770), cuyo tema básico es "la Historia del hombre natural cuyo hábitat principal es América pero que se puede encontrar en otras partes en regiones sometidas a las mismas condiciones climáticas».
} 
sin elevación de espíritu, no hemos dejado nada a la imaginación, presentando este retrato. (1770: tomo I, p. xiii) ${ }^{20}$

En contraposición a este anti-americanismo, Gilij se confronta con la concepción del "buen salvaje", el modelo del "hombre natural" de Rousseau y también aquí polemiza contra esta visión idealizada del hombre americano, que vive supuestamente en total armonía con su ambiente natural.

Frente a tantas controversias europeas, el misionero jesuita pretende dar una visión que califica de correcta, objetiva, libre de todo prejuicio y basada exclusivamente en la observación directa, como testigo ocular que fue:

[...] quiero ser juez imparcialísimo de los indios, no despreciándolos a ciegas, como han acostumbrado algunos, ni alabándolos más que cuanto merecen. En los largos años que habité con ellos, siempre vi mucho de loable y también mucho de reprensible. Me servirá de regla escribir lo que de ellos observé atentamente, no los prejuicios, no el ánimo ganado por la lectura de autores contrarios o favorables a los indios. (1965: II, 109).

Se propone mostrar a los orinoquenses con sus virtudes y sus defectos, adoptando una actitud ponderada, más realista y relativamente moderna, de respeto y en algunos casos de admiración por la paciencia, el buen hablar y sobretodo la vida simple de los orinoquenses, alejada de "la insaciable hambre del oro".

En América, como en cualquier otra parte del mundo, hay bueno y malo, comarcas ricas y pobres, países sanos y enfermizos, cielo hermoso y cielo feo, tierra fértil e infecunda, llanuras y montes como en nuestra tierra. (1965: I, 15)

Pero Gilij no fue siempre el intérprete imparcial y objetivo que pregonaba; en las situaciones que presenció no pudo desprenderse del todo de los estereotipos, anclados en la mentalidad de su época y que perduran hasta el siglo XX, considerando al indio como un ser perezoso, amoral, desorganizado. Matizó en varias oportunidades estos juicios, objetando en particular el calificativo de "bárbaro", comúnmente utilizado en la literatura etnográfica, advirtiendo contra el procedimiento de "pretender que los bárbaros, como algunos hacen, son perversos en todo sin mezcla de bien, privarles neciamente incluso de aquellas luces que el Señor por todas partes como padre común difunde" (1965: II, 110).

\footnotetext{
${ }^{20}$ Cornelius de Pauw, Recherches Philosphiques sur les Américains: “Si nous avons dépeint les Américains comme une race d'homme qui ont tous les défauts des enfants, comme un espèce dégénérée du genre humain, lâche, impuissante, sans force physique, sans vigueur, sans élévation d'esprit, nous n'avons rien donné à l'imagination en faisant ce portrait [...]". Tomo I, primera parte, Discurso Preliminar, p. xiii.
} 


\section{Un precursor de la lingüística amerindia}

Gilij confesó en muchas oportunidades su fervoroso y constante interés ${ }^{21}$ por las lenguas, no sólo las de la Orinoquia, que tuvo la oportunidad de escuchar y analizar, sino también las de América en general, sobre las cuales recogió abundantes y muy variadas informaciones, procuradas entre los más diferentes autores. De hecho, dedicó todo el libro tercero del tomo III de su Ensayo de Historia Americana a las lenguas orinoquenses y americanas, demostrando una extraordinaria competencia en el abordaje de estas lenguas, tan diferentes de su italiano materno, del latino y de todas las lenguas europeas que había podido conocer.

Sobre las lenguas orinoquenses existen, de hecho, pocos datos lingüísticos anteriores a Gilij. Los primeros estudios se remontan a la segunda mitad del siglo XVII y tratan, en su mayoría, acerca de las lenguas de tres pueblos caribes muy emparentados, de la costa oriental de Venezuela. Estos trabajos fueron también obra de misioneros, a saber, de Pierre Pelleprat, Manuel de Yangüez, Matias Ruiz Blanco y Francisco de Tauste. ${ }^{22}$ Aun cuando estos textos representan un material importante para el estudio de las lenguas caribes de Venezuela, no dejan de ser meros esbozos gramaticales y/o listas de palabras con breves oraciones, de lectura a veces árida y de alcance muy limitado.

La obra de Gilij, en cambio, conoció una amplia difusión desde su publicación, en 1782, entre los estudiosos de diversas disciplinas, pero en particular entre los gramáticos y filólogos del siglo XVIII y XIX. Recibió los elogios de numerosos lingüistas que no sólo celebraron el valor científico y novedoso de sus descubrimientos lingüísticos, sino que los utilizaron como base de datos para sus propias investigaciones. Es el caso de su amigo lingüista, también jesuita, Lorenzo Hervás y Panduro (1735-1809), que en su Catalogo de las lenguas de las naciones conocidas y numeración, división y clase de estas según la diversidad de sus idiomas y dialectos (1800-1804) reconoció su deuda con Gilij:

Me valdré principalmente de la excelente historia que ha publicado el esclarecido Abate Don Felipe Gilij que ha sido misionero de algunas

\footnotetext{
21 "Yo era todo ojos y también todo oídos para observar toda mínima particularidad de las lenguas" (1965: III, 253).

${ }^{22}$ Pierre Pelleprat. Relation des Missions des Pères de la Compagnie de Jésus, dans les Isles et dans la terre ferme de l'Amérique méridionale. Une introduction à la langue des Galibis (1655); Manuel de Yangüez Principios y Reglas de la lengua cumanagota, general en varias naciones que habitan la provincia de Cumana (1676); Matías Ruiz Blanco Diccionario fe la lengua de los Indios Cumanagotos y Palenques (1683) y Reglas para la inteligencia de la lengua de los Indios de Píritu (1690); Francisco de Tauste Arte y vocabulario de la lengua de los Indios Chaymas, Cumanagotos, Cores, Parias y otros diversos de la Provincia de Cumaná (1698).
} 
naciones del Orinoco. No contento yo con haber observado todo lo que en dicha historia se dice sobre las lenguas y que justamente ha merecido el aplauso universal de los literatos. [...] valiéndome de las noticias que sobre las lenguas da el señor Gilij en su obra intitulada Ensayo de Historia Americana, he formado la relación que inmediatamente haré de los idiomas que se hablan por las naciones del Orinoco [...] siguiendo el orden con que el señor Gilij en el citado capitulo XII del libro III de su tomo II trata de las lenguas del Orinoco (1800, vol. I, p. 202-204, subrayado por nosotros).

Los testimonios de aprecio y felicitaciones por la riqueza y la seriedad de su obra, provenientes de expertos de toda Europa no se hicieron esperar. En el tomo III del Ensayo de Historia Americana Gilij incorpora parte de una carta que August Ludwig von Schlözer, profesor de historia y política de la Universidad de Göttingen, le mandó en 1782, poco antes de la publicación de la obra:

Por tus escritos de las cosas del Orinoco, te felicito [...] principalmente lo que dices en tu tomo tercero sobre las lenguas americanas [...]. Hace poco hemos investigado los idiomas de cada nación, hemos distinguido las lenguas matrices de los dialectos [...]. Quedaba el mundo americano. Tú nos lo abres, varón eruditísimo, y nos enseñas de pueblos antes apenas conocidos de nombre; y no sólo nos las enseñas, sino que lo que nadie hizo antes que tú, sobre ellas filosofas y filosofas con sobriedad. (Gilij 1965: III, 281; subrayado por nosotros)

El propio Alexander von Humboldt (1769-1859) incorporó en su Viaje a las regiones equinocciales del Nuevo Continente (1814-1825) algunos de los análisis lingüísticos de Gilij, en particular las afinidades entre las lenguas Caribes de la costa oriental y las del Orinoco medio (Humboldt 1985; tomo II, capítulo IX, p.181-205). Y Charles Leclerc, el editor francés de la Bibliotheca Americana escribió en 1878 acerca de la obra de Gilij: "Su libro, uno de los mejores a consultar para la historia del indio del Orinoco, se ha vuelto raro. El tercer volumen sobretodo merece ser señalado para la historia de la lingüística Americana" 23

La obra de Gilij tuvo, sin duda alguna, una influencia sobresaliente en la etnohistoria y etnolingüística de Venezuela, y ésta llega hasta nuestros tiempos. El lingüista Ángel Rosenblat (1902-1984), en su trabajo "Los Otomacos y Taparitas de los Llanos de Venezuela (1964), fundamentó su análisis comparativo otamacos-taparitas a partir de los datos léxicos, gramaticales y fonéticos extraídos principalmente de las obras de Gilij y de Gumilla.

Ante la diversidad, la cantidad y la particularidad de las lenguas americanas, Gilij se planteó el problema del origen de tantas lenguas desde sus primeros

${ }^{23}$ Bibliotheca Americana. Histoire I, Géographies, Voyages, Archeologie et Linguistique des deux Amériques et des îles Philippines. Paris, 1878, núm. 238, p.186-187. 
contactos con los pobladores orinoquenses,: “además del origen, la variedad de las lenguas que se hallan en el Nuevo Mundo llama naturalmente la atención" (1965: III, 225).

Como buen conocedor de los textos bíblicos, recurrió a la doctrina teológica, según la cual todo, las lenguas entre otras tantas cosas, fue creado por Dios. Además no podía dejar de recordar el muy célebre texto dedicado a la Torre de Babel, ${ }^{24}$ según el cual Dios castigó la soberbia de los hijos de Noé, dispersando y diferenciando las lenguas, de modo que no pudiesen entenderse. Sin embargo, a pesar de creer en la monogénesis del lenguaje y de las lenguas, conforme a la enseñanza bíblica, entendió que las lenguas americanas tenían características específicas, de modo que no podían ni debían analizarse a la luz del latín o de otras lenguas ya conocidas, como el hebreo. Expresó claramente en su obra este principio metodológico, sumamente moderno para aquella época:

[...] de las lenguas indias no se saben aún bien el origen, ni por qué medio ni cómo pasaron del antiguo continente a América. Por lo cual es necesario aprenderlas de manera que dejando toda especie de latinismo, no se crea que hay que obligarlas a servir a éste contra la voluntad de ellas mismas. Yo, cuando comencé a aprender el tamanaco, fingí que no tenía idea de otras lenguas y me resultó bien. (1965: III, 169)

Su análisis sincrónico de las lenguas Tamanaco y Maipure es la demostración más convincente de su auténtica competencia como lingüista. Gilij manifiesta un don de observación excepcional, aflorando ya algunos conceptos que pasarán a ser fundamentales en la lingüística del siglo $\mathrm{XX}$, como la variación combinatoria o alofonía, la distribución sistemática o la estructura silábica que el estructuralismo desarrollará. En su análisis fonético del Tamanaco, por ejemplo, identifica la ocurrencia de alófonos entre oclusivas sordas y sonoras, también entre oclusivas y oclusión glotal, ambos fenómenos muy difundidos en las lenguas caribes. Distingue con bastante perspicacia algunos fonos cuyas características articulatorias eran prácticamente desconocidas en aquella época, como las vocales posteriores [ё], [ï]. Hace unos breves comentarios referentes a la distribución de las vocales en determinadas lenguas, abriendo pistas de investigación sobre la estructura silábica y la prosodia.

\footnotetext{
24 "Mas por decir ahora lo que me he propuesto, esto es el origen de las lenguas del Orinoco, no sabría hallar otro para ellas que el divino [...] nos damos cuenta en seguida de que el hablar del hombre, que ha sido el mismo para todos antes del diluvio, se hizo vario y múltiple al edificarse la famosa torre de Babilonia. Dios mismo, confundiendo la humana soberbia, dio el primer empuje a las lenguas el cual, cumpliendo los elevados designios divinos, llevó suavemente a los hombres a poblar las diversas partes del globo terrestre" (1965: III, 126).
} 


\section{Trabajos de clasificación: las familias Caribe y Maipure (Arawak)}

Además del enfoque sincrónico, Gilij experimenta el método comparativo, buscando las correspondencias lexicales y midiendo el grado de mutua comprensión para descubrir las afinidades genéticas entre las lenguas. He aquí un ejemplo de algunas lenguas caribes:

Quien sabe el tamanaco comprende el pareca [...] más diferente de los tamanacos es la lengua de los avaricotos, pero también sabida la primera resulta inteligible [...] No son demasiado diferentes los mapoyes [...] hasta aquí la dificultad de aprender las lenguas es ligera. (1965: III, 172)

A Gilij le corresponde el notable mérito de haber elaborado la primera clasificación de las lenguas orinoquenses y de haber descubierto dos de las principales familias lingüísticas presentes en el continente sudamericano: la Caribe, que Gilij descubrió a partir de su conocimiento del tamanaco, y la Maipure o Arawak, a partir de su conocimiento del maipure.

Supe antaño dos lenguas nada semejantes entre sí. Supe también los dialectos que de ellas, más o menos alterados, se derivan: En las lenguas de los tamanacos y de los maipures, instruidos por mi en la fe, tuve, por decirlo así, las llaves de casi todas las naciones orinoquenses. (1965: III, 135)

En el caso de la familia caribe, su gran logro radica en haber encontrado afinidades entre el tamanaco y las lenguas caribes habladas en territorios relativamente lejanos del tamanaco, como el chaima, el cumanagoto, el pariagoto de la costa oriental de Venezuela, el ye'kwana, que Gilij llama "maquiritare", presente en los ríos Caura, Ventuari, Padamo, Cunucunuma y Orinoco, el arevariano, posiblemente yawarana, ubicado en los ríos Manapiare, Parucito y Majagua. En el caso de la familia arawak, quizás la más extensa del continente sudamericano, su logro fue haber relacionado la lengua de los Mojos de Bolivia y la de los Maipures del Orinoco.

[...] no dejo de ver que tanto entre mojos como entre maipures hay también palabras diferentes entre sí, y acaso lo son la mayoría. ¿Pero qué importa esta para no decir que vienen de la misma fuente? [...] Por lo demás la lengua moja conserva todavía rasgos de la maipure. (1965: III, 276)

Más tarde Karl den Steinen (1855-1929) se inspiró de Gilij al estudiar el bakairi, una lengua caribe hablada en el río Xingu:

Si los Bakairi resultan caribes, aparecerá bajo una nueva luz la completamente análoga y memorable observación de Gilij de que los 
Mojos de Bolivia están emparentados con los Maipures del Orinoco. Así como los Mojos se encuentran en un nivel más bajo de cultura que los pueblos del Orinoco de igual manera todavía hoy día los Bakairi salvajes están sin duda atrasados frente a sus parientes de Guayana. $(1886: 290)^{25}$

En los siglos XIX y XX hubo grandes avances en la clasificación de las lenguas amerindias, con el auge de la gramática comparativa. Sin embargo, la mayoría de los clasificadores reconocieron los aciertos de Gilij en lo que concierne las familias caribe y arawak. Algunos, como Lucien Adam (18331918), ${ }^{26}$ utilizaron varios de sus planteamientos en estudios de gramática comparada de las lenguas caribes.

De forma general, es justo llamar la atención sobre la postura crítica y, en muchos aspectos, vanguardista de Gilij, que denuncia las apreciaciones negativas y los prejuicios perpetuados por viajeros, cronistas y misioneros desde el inicio de la colonización. Para muchos de ellos las lenguas indígenas eran rudimentarias, simples, incapaces de transmitir ciertos conceptos y ciertos conocimientos, y muchos misioneros juzgaban que eso representaba un fuerte freno a la evangelización. Algunos hasta pensaron que dichas lenguas eran productos del propio “demonio" (1965: III, 227) 27. Gilij denuncia abiertamente estas opiniones, promoviendo, más bien, el uso de las lenguas indígenas para el proceso evangelizador ${ }^{28}$, la elaboración de diccionarios y gramáticas de estas lenguas en su correspondiente idioma indígena, poniendo de relieve la riqueza y hasta la belleza (1965: III, 240) de su vocabulario.

Todos los orinoquenses en las cosas que conocen son muy ricos en expresiones varias. Quedé muchas veces admirado de que gente educada en las selvas hablase también. Son ordenadísimas sus lenguas

\footnotetext{
${ }^{25}$ Karl von den Steinen Durch Central-Brasilien. Expedition zur Erforschung des Schingú im Jahre 1884. Leipzig, 1886; p. 290. En 1892, Steinen confirma definitivamente las conclusiones de Gilij, en su amplio estudio de la lengua Bakairi Die Bakaïri-Sprache: Wörterverzeichnis, Sätze, Sagen, Grammatik; mit Beiträgen zu einer Lautlehre der karaïbischen Grundsprache. Leipzig: Koehler, 1892.

${ }^{26}$ Matériaux pour servir à l établissement d'une grammaire comparée des dialectes de la famille caribe. Paris, 1893.

27 "No es creíble en qué horribles imaginaciones hayan venido dar algunos antiguos escritores de América, aturdidos, por decirlo así, por el número innumerable de las lenguas $\mathrm{y}$ de los diversos modos de hablar que en ella se hallan. Y no sabiendo, o no pudiendo acaso por falta de tiempo, dar con su número preciso, ya que no con su verdadero origen dijeron que son infinitas las lenguas americanas, y que su autor es el demonio y ya no los indios" (1965: III, 227).

${ }^{28 "}$ "Yo soy de contrario parecer, y digo que los bárbaros (aunque se le enseñe razonablemente el español) no entienden nada las oraciones que en se enseña en lengua extraña" (1965: II, 160).
} 
y llenas de graciosa armonía; y en todo su hablar demuestran un intelecto no sólo bueno sino que su lengua, como las otras matrices, desciende de una antigua e intacta fuente. (1965: III, 168)

Entre las virtudes de las lenguas americanas, resalta con énfasis la "abundancia de verbos, tiempos, modos", la "variedad de tonos, de acentos" según los idiomas, la "cualidad de habla", principalmente el habla de los ancianos y de los chamanes.

El estudio de la diversidad lingüística conduce a Gilij a atribuir un papel preponderante a la lengua como rasgo esencial de distinción étnica. Para él la lengua es la marca fundamental de la identidad de un pueblo."[...] este es según mi parecer el único signo justo con que se puede separar los indios entre sí: $\underline{\text { la }}$ total diferencia de idioma (1955: IV, 211).

Los criterios de identidad étnica fueron objeto de muchas discusiones en el siglo pasado, y hoy la lengua no es ni suficiente ni necesaria para definir la identidad de un pueblo. Sin embargo la posición de Gilij nos parece de mucha actualidad, dada la importancia que las minorías étnicas otorgan hoy en día a sus derechos lingüísticos.

\section{A manera de conclusión}

En esta breve reseña no fueron presentadas todas las múltiples facetas de la obra de Gilij. Algunos temas de relativa importancia no fueron abordados, como su concepción de la labor misionera, el análisis de la colonización española y del poblamiento, la percepción de una sociedad criolla en incipiente desarrollo, la visión prospectiva del continente americano y de Europa con este nuevo intercambio de conocimientos. Hemos querido resaltar el carácter universal de su obra por la extraordinaria diversidad de los temas tratados, su indiscutible competencia, la originalidad y calidad de sus informaciones, sus descubrimientos lingüísticos, algunos incluso con un valor vanguardista. Gilij fue ante todo un "precursor" en diversos campos de las investigaciones americanistas y, sobretodo, un "humanista", con un profundo respeto por los pueblos originarios y sus respectivas culturas. En este sentido, su Ensayo de Historia Americana puede ser considerado como uno de los testimonios más valiosos y contundentes acerca del estado del así llamado "Nuevo Mundo", y de la percepción que se tenía de él en el siglo XVIII.

\section{Bibliografía}

Arvelo-Jiménez, Nelly y Bjord, Horacio. 1989. Reflexiones antropológicas sobre "el Ensayo de Historia Americana" de Felipe Salvador Gilij. Montalbán, Caracas 21:69-90. Bicentenario de Filippo Salvatore Gilij 1789-1989. Universidad Católica Andrés Bello. 
Bjord, Horacio. 1985. El contexto multilingüe del sistema de interdependencia regional del Orinoco. Antropológica 63-64:83-101. Caracas.

Caulin, Antonio. 1992 [1779]. Historia Corográfica de la Nueva Andalucía. Biblioteca de la Academia Nacional de la Historia. Fuentes para la Historia Colonial de Venezuela. Caracas; 2 vols.

Cunill Grau, Pedro. 1989. Felipe Salvador Gilij, geógrafo dieciochesco de la cuenca del Orinoco y del Amazonas venezolano. Montalbán, Caracas, 21 (1989), p. 21-68. Bicentenario de Filippo Salvatore Gilij 1789-1989. Universidad Católica Andrés Bello.

De Pauw, Cornelius. 1770. Recherches Philosophiques sur les Américains ou Mémoires intéressants pour servir à l'Histoire de l'Espèce Humaine. Berlín.

Donis Ríos, Manuel Alberto. 1989. Felipe Salvador Gilij y la Cartografía de la Orinoquia. Montalbán 21:209-230. Bicentenario de Filippo Salvatore Gilij 17891989. Caracas, Universidad Católica Andrés Bello.

Gilij, Felipe Salvador. 1955 [1782]. Ensayo de Historia Americana o sea historia natural, civil y sacra de los reinos y de las provincias españolas de Tierra Firme en la América Meridional. Vol. IV. Traducido por Mario Germán Romero y Carlo Bruscantini. Biblioteca de Historia Nacional, Bogotá.

Gilij, Felipe Salvador. 1965 [1782]. Ensayo de Historia Americana o sea historia natural civil e sacra de los reinos de las provincias españoles de Tierra Firma en la América Meridional. Vols. I, II, III. Traducidos por Antonio Tovar. Biblioteca de la Academia Nacional de la Historia Nacional Caracas.

Gumilla, José. 1963 [1731]. El Orinoco Ilustrado y Defendido, historia natural, civil, y geographica de este gran rio, y de sus caudalosas vertientes: govierno, usos, y costumbres de los Indios, sus habitadores, con nuevas y útiles noticias de animales, árboles, frutos, aceites, resinas, yervas, y raíces medicinales. Biblioteca de la Academia Nacional de la Historia Nacional, Caracas.

Hervás y Panduro, Lorenzo. 1800-1805. Catálogo de las lenguas de las naciones conocidas y enumeración, división y clases de estas según la diversidad de sus idiomas y dialectos. Madrid; 6 vols.

Humboldt, Alexander von. 1985 [1814-1825]. Viaje a las Regiones Equinocciales del Nuevo Continente. Traducción de Lisandro Alvarado. 5 Tomos. Caracas: Monte Ávila Editores.

Mattei-Müller, Marie-Claude. 1989. “Gilij, pionero de la etnolingüística venezolana: sus métodos y sus logros”, Montalbán, Caracas, 21 (1989), p. 91-104. Bicentenario de Filippo Salvatore Gilij 1789-1989. Universidad Católica Andrés Bello.

Mattei-Müller, Marie-Claude y Paul, Henley. 1989. Los Tamanaku, su Lengua, su Vida. Universidad Católica del Táchira, Caracas.

Pérez Fernández, Francisco Javier. 1989. Testimonios venezolanos sobre la obra lingüística de Felipe -salvador Gilij. Montalbán 21:179-202. Bicentenario de Filippo Salvatore Gilij 1789-1989. Caracas, Universidad Católica Andrés Bello. 
Steinen, Karl von den. 1886. Durch Central-Brasilien. Expedition zur Erforschung des Schingú im Jahre 1884. Leipzig: Brockhaus.

Data recebimento: 05/11/2014.

Data aceite: $20 / 11 / 2014$. 